\title{
Tracheal rupture after emergency endotracheal intubation
}

\author{
Giovanni Volpicelli • Luciano Cardinale • \\ Francesco Ardissone
}

Received: 16 May 2009 / Accepted: 23 September 2009 /Published online: 20 November 2009

(C) Springer-Verlag London Ltd 2009

A 60-year-old woman presented to the emergency department (ED) of a suburban hospital with complaints of cough, fever, and dyspnea. She had a history of chronic obstructive pulmonary disease (COPD) and chronic steroid therapy. At presentation, she was in severe respiratory distress. Orotracheal intubation was decided due to persistence of severe hypoxia and hypercapnia with deterioration of consciousness despite a first attempt at noninvasive ventilation. The intubation was performed in rapid sequence using a $7.5-\mathrm{mm}$ diameter single lumen tube without stylet. The patient had a regular and anatomically intact airway. The maneuver itself was reported to be an easy procedure and was considered successful after the first attempt. After about an hour of invasive ventilation, a subcutaneous emphysema appeared on the neck and anterior chest wall, respiratory failure worsened, and a slight hemoptysis occurred. The chest radiograph showed subcutaneous emphysema and protrusion of the cuff outside the tracheal lumen (Fig. 1). A computed tomography

Fig. 1 a Chest radiograph in the anteroposterior view of the patient with tracheal rupture, showing subcutaneous and mediastinal emphysema. b Detailed view shows the protrusion of the cuff of the tube outside the tracheal lumen (white arrows)
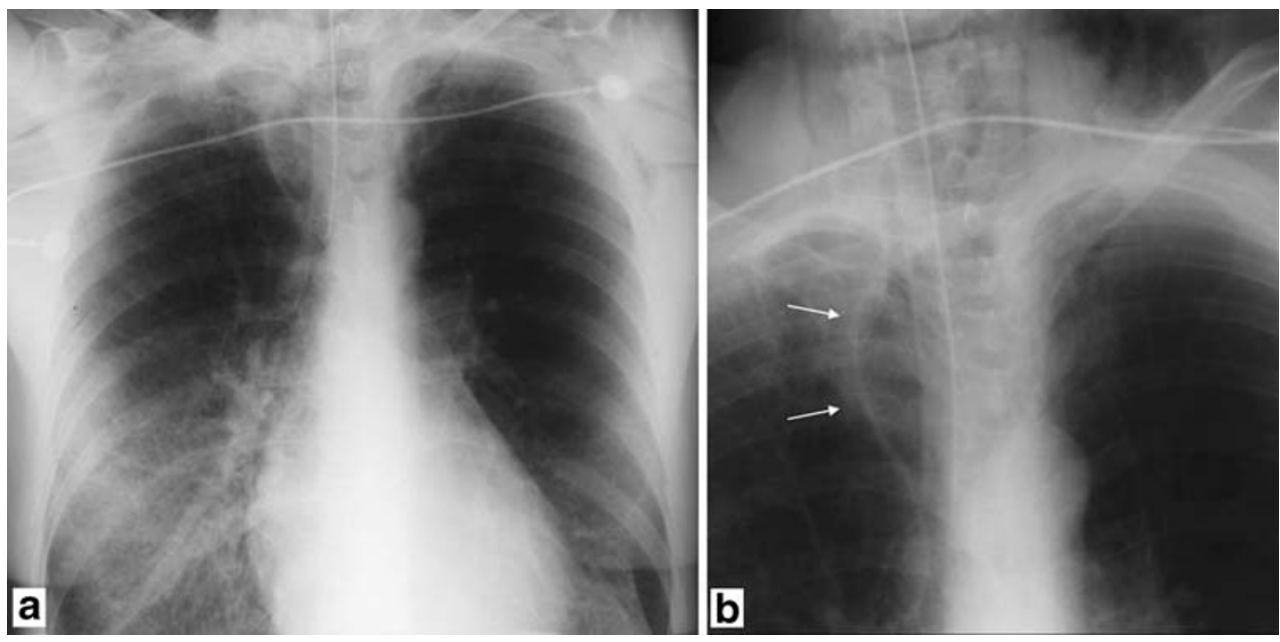

G. Volpicelli $(\bowtie)$

Department of Emergency Medicine,

San Luigi Gonzaga University Hospital,

Regione Gonzole 10,

10043 Orbassano,

Turin, Italy

e-mail: gio.volpicelli@tin.it
L. Cardinale

Institute of Radiology, San Luigi Gonzaga University Hospital, Orbassano, Turin, Italy

\section{F. Ardissone}

Department of Thoracic Surgery,

San Luigi Gonzaga University Hospital, Orbassano, Turin, Italy 

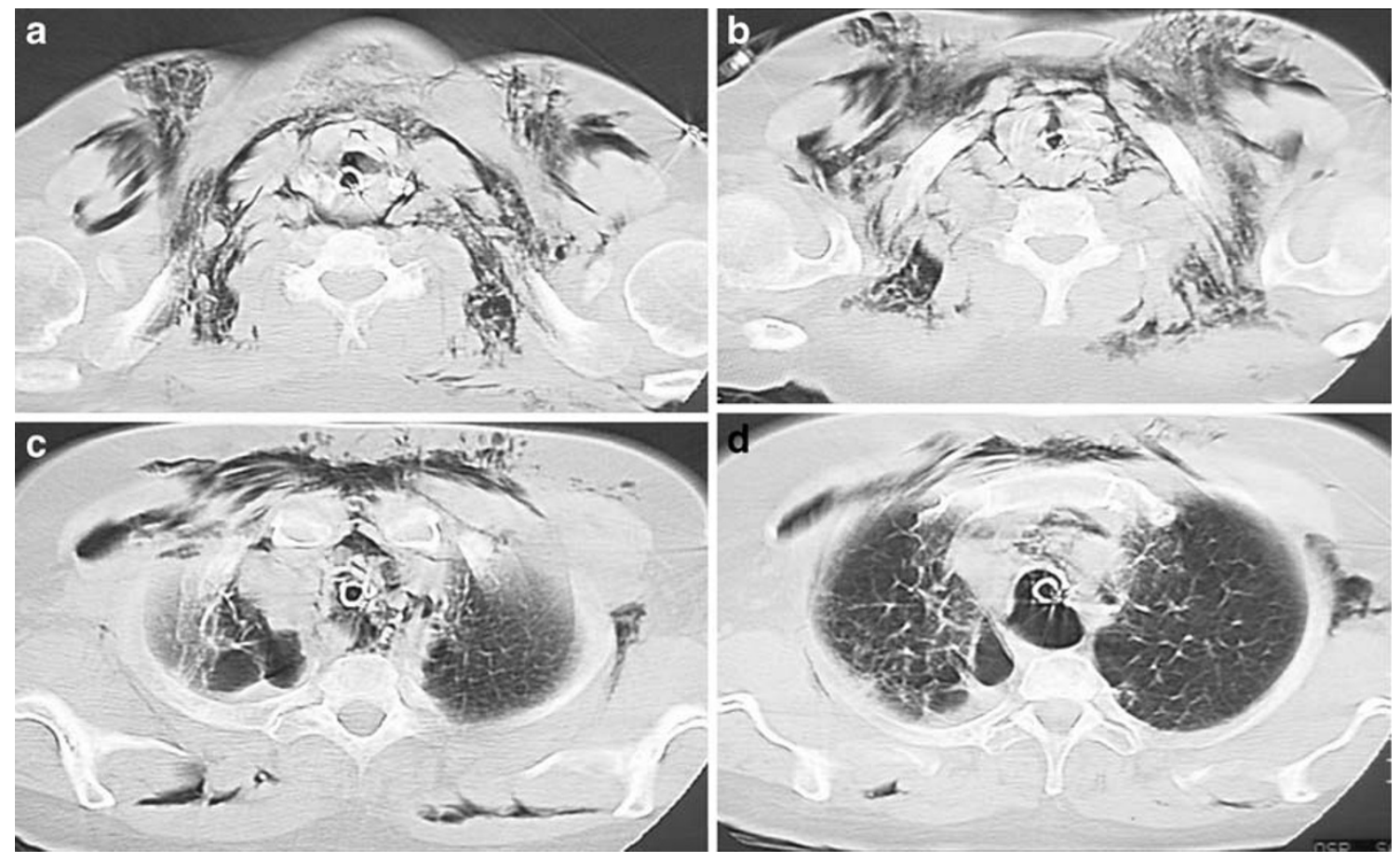

Fig. 2 a-c Corresponding CT axial scans corroborating the diagnosis of subcutaneous and mediastinal emphysema. d The lumen of the tracheal tube appears enlarged and deformed after the herniation of the cuff

(CT) scan visualized the injury of the posterior tracheal wall due to the rupture of the pars membranacea (Fig. 2). The patient was then referred to our hospital to undergo a bronchoscopy, which revealed a longitudinal hole with sharp margins at the posterior part of the membranous portion, extending up to $2 \mathrm{~cm}$ from the carina with a total length of $5 \mathrm{~cm}$. The lesion was surgically repaired via right thoracotomy.

Mechanisms that may determine tracheal laceration are mechanical and anatomical [1]. An over-distended balloon cuff coupled with fragility of the tracheal wall due to chronic lung diseases and steroid therapy may be crucial [2]. The appearance of specific symptoms after intubation, like subcutaneous emphysema, hemoptysis, and persistence of hypoxia despite adequate ventilation, are consistent with a possible tracheal rupture [1-4]. Radiology may confirm the clinical suspicion.

\section{References}

1. Marty-Ané CH, Picard E, Jonquet O et al (1995) Membranous tracheal rupture after endotracheal intubation. Ann Thorac Surg 60:1367-1371

2. Massard G, Rougé C, Dabbagh A et al (1996) Tracheobronchial lacerations after intubation and tracheostomy. Ann Thorac Surg 61:1483-1487

3. Borasio P, Ardissone F, Chiampo G (1997) Post-intubation tracheal rupture. A report on ten cases. Eur J Cardiothorac Surg 12:98-100

4. Kaloud H, Smolle-Juettner FM, Prause G et al (1997) Iatrogenic ruptures of the tracheobronchial tree. Chest 112: 774-778 